\title{
VOLT-TIME CHARACTERISTICS OF SHORT AIR GAPS UNDER NONSTANDARD LIGHTNING VOLTAGE WAVES
}

\author{
P. Chowdhuri, A.K. Mishra \\ Tennessee Technological University \\ Cookeville, TN 38505
}

and

\begin{abstract}
The voll-time characteristics of $5 . \mathrm{cm}$ long rod-plane and rod-rod air gaps were experimentally determined with five different waveshapes of the applied impulse voltage. The front time of the waves was varied from 25 ns to $10 \mu \mathrm{s}$, and the time to half value was varied from $0.5 \mu \mathrm{s}$ to $100 \mu \mathrm{s}$. The volt-time characieristics were also checked analytically using the concept of disruptive effect. The parameters for the disruptive effect were experimentally determined.
\end{abstract}

\section{INTRODUCTION}

The breakdown voltage level of a dielectric system under a transient voltage of a given waveshape is not a constant parameter. When transient voltages of the same waveshape but of increasing amplitude are applied to a dielectric system, the dielectric breaks down at higher voltage levels at shorter time delays for the higher applied voltages. This characteristic, known as the volt-time or time-lag characteristic, significantly influences the insulation coordination of an electric power system. The volt-time characteristic is different for the same dielectric system under transient voltages of different waveshapes. The volt-time characteristic of a dielectric system for the standard $1.2 / 50$ - $\mu$ s lightning voltage is generally determine such a volt-time characteristic.

The volt-time characteristics under nonstandard lightning voltages are seldom available, even though a dielectric system is mostly stressed by such lightning voltages in practice. Many attempts have been made in the past to analytically derive the volt-time characteristics under nonstandard lightning voltages from the known standard volt-time characteristic. available. However, a large number of tests are required to

In dealing with the time-lag characteristics of transformers under nonstandard lightning voltages, Witzke and Bliss introduced the term "disruptive effect", DE [1,2]. Disnuptive effect has since then been used to define the volt-time characteristics of dielectric systems in general. The general form of the equation defining the disnptive effect is:

$$
D E=\int_{t_{0}}^{t_{b}}\left[V(t)-K_{2}\right]^{K_{2}} \cdot d t,
$$

where $\mathrm{V}(\mathrm{t})$ is the applied impulse voltage, $\mathrm{DE}, \mathrm{K}_{1}$ and $\mathrm{K}_{2}$ are constants for a dielectric system, $t_{0}$ is the time lag of breakdown, and $t_{0}$ is the time when $V\left(t_{0}\right)=K_{1}$. With the assumption that $D E$ is constant, it can be evaluated from tests with the standard $1.2 / 50-\mu \mathrm{s}$ impulse voltage. However, difficulties have been encountered in the determinarion of $K_{3}, K_{2}$ and $t . K_{1}$ has been varied from zero to the static withstand voltage level of the insulation system; $K_{2}$ has been assumed to be 1 or 2 ; and, to has been assumed to be zero for simpliciry. As a result, it has not been possible to apply (1) universally, and no acceptable method exists today. A comprehensive review of the volt-time characteristics has been published previously $[3,4]$.

The goal of the present study was to perform a series of statistically designed tests on several types of short air gaps under lightning voltages of front times varying from the nanoseconds regime to the microseconds regime. The objective was to compare the critical breakdown voltage levels, $v_{50,}$ and the volt-time characteristics of these short air gaps under lightning voltages of various waveshapes. The results of the critical breakdown voltages were presented previously [5]. The results of the volt-time characteristics of these air gaps are presented in this paper.

\section{EXPERIMENTS}

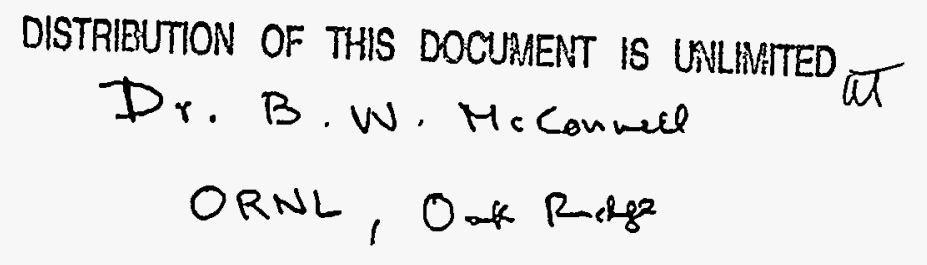

Two vertically mounted 5-om long air gaps were selected for the tests: (i) rod-plane gap, and (ii) rod-rod gap. The rods were $1.25-\mathrm{cm}$ square, square-cut aluminum rods; and the plane was a l-m square aluminum plate. The test gaps were mounted in direct line of sight of the spark gaps of the impulse generator, located a few meters away, thus being exposed to the UV light emitted by these spark gaps.
The submitted manuscript has boen suthored by a contractor of the U.S. Government under contract No. DEACO5-840R2 1400. Accordingly. the U.S. Govemment retains a nonexclusive, royalty-free license to publish or reprochuce the published form of this contribution, or allow others to do so, for U.S. Government purposes."

\author{
B.W. McConnell
Oak Ridge National Laboratory \\ Oak Ridge, TN 37831-6070
}


Eight voltage waveshapes of both polarities were selected for the cvaluation of $V_{\text {so. }}[S$ ], of which five waveshapes were used to determine the volt-time characteristics of the air gaps. The wavefronts were varied from $25 \mathrm{~ns}$ to $10 \mu \mathrm{s}$, and the wavetails to half value were varied from $0.5 \mu \mathrm{s}$ to $100 \mu \mathrm{s}$. The individual waveshapes used for the determination of the volt-time characteristics are shown in Table 1.

TABLE I: TEST IMPULSE WAVESHAPES

\begin{tabular}{|c|c|c|c|c|c|}
\hline & \multicolumn{5}{|c|}{ Wave Number } \\
\hline & 1 & 2 & 3 & 4 & 5 \\
\hline Front, $\mu \mathrm{s}$ & 0.025 & 0.025 & 0.12 & 1.2 & 10 \\
\hline Tail, $\mu s$ & 0.5 & 25 & 25 & 50 & 100 \\
\hline
\end{tabular}

Tests were started at a charging voltage level of the impulse generator where the rest gap broke down on the tail of the applied voltage wave. The charging voltage level was progressively increased until the test gap broke down on the front of the applied voltage with very short time lag. Ten shots were applied at each charging voltage level. The mean of the 10 time lags of breakdown at each charging voltage level was then plotted against the peak of the applied voltage when the breakdown occurred on the tail of the applied voltage, and against the actual voltage at breakdown for breakdown on the front of the applied voltage.

\section{ANALYSIS}

The volt-time characteristic of each of the test gaps was also analytically determined from two breakdown tests at two different applied voltage levels by the following empirical equation:

$$
D E=\int_{l_{0}}^{l_{0}}\left[V(t)-V_{0}\right]^{\alpha \frac{V(t)}{V_{0}}} \cdot d t,
$$

where $\alpha$ and $V_{0}$ are two constants to be determined from two experimental points; $t_{0}$ is the time (from start) when the instantaneous applied voltage exceeds $V_{o}$ and $t_{b}$ is the time when the applied voltage collapses due to breakdown. DE (disnuptive effect) is a parameter which is constant for a particular gap under a specified voltage waveshape. Equation 2 is similar to (1) thus assuming that the breakdown process is a cumulative process in voltage and time. However, (2) is different in interpreting the breakdown mechanism. It quantifies the breakdown process by assuming that $D E$ is a constant parameter of a particular gap under a specified voltage waveshape, irrespective of the magnitude of the voltage. DE will assume different values for different gaps, and for different voltage waveshapes even for the same gap. $V_{0}$ has been assumed by various researchers as the de withstand voltage, power-frequency withstand voltage or even zero. Equation 2 proposes that $V_{0}$ is a parameter which is constant for a particular gap under a specified voltage waveshape, and that it needs to be determined by statistical analysis. The exponent of the voltage in the expression for $D E$ has been assumed by others as constant. In contrast, (2) proposes that this exponent is a function of the overvoltage factor $\left(=V(t) / V_{D}\right)$. This assumption stems from the fact that the velocity of the propagating streamer (leader) in the air gap is higher the higher the electric field (i.e., the applied instantaneous voltage) is. The parameter, $a$, will vary with the type of the air gap and the waveshape of the applied voltage. Therefore, both $V_{0}$ and $\alpha$ need to be determined for each setup. As no theoretical basis has been arrived as yet, $V_{0}$ and $\alpha$ were experimentally derived.

$V_{0}$ is defined as the voltage of a specified waveshape which a particular air gap will withstand under repeated applications with very low probability of breakdown. If the estimates of the critical breakdown voltage, $V_{S o}$, and the standard deviation, $s$, are known, based on $\mathrm{n}$ observations of a normal distribution, then it can be stated that at least a portion, $P$, of the population is greater than $V_{0}$ with confidence, $\gamma$, where $V_{0}$ is given by:

$$
V_{0}=V_{s 0}-k \times s \text {. }
$$

The parameter, $k$, which is a function of $n, P$ and $\gamma$, can be found from statistical tables [6]. $P$ was assumed to be 0.999 , and $\gamma=0.95$.

Once $V_{0}$ is computed, there still remain two unknowns in (2): $D E$ and $\alpha$. These two parameters were computed from two breakdown voltage levels at two different breakdown times, the voltage profiles $(V(t) v s . t)$ of which were already stored in the computer. The integral in (2) was evaluated for each of the two breakdown voltages for various values of $\alpha$. The correct value of $\alpha$ would produce equal $D E$ for the nwo $V(t)$. Once $D E, V_{0}$ and $\alpha$ are determined for a particular gap under a specified voltage waveshape, the volt-time characteristic of the air gap under the specified voltage wave is determined as follows. The full-wave voltage profile which is stored in the computer is multiplied by a factor greater than 1 . Using this $V(t)$, the integration in (2) is performed up to a time, $t_{\text {b }}$ when the numerical value of $(2)$ is equal to the specifed $D E$. The peak value of the voltage and $t_{0}$ provide one point on the volt-time curve. This step is repeated with increasing values of the miltiplying factor to compute other points on the volt-time characteristic. The analysis was performed with the ASYSTANT software, installed in the HP Vectra personal computer. This software can perform mathematical operations on data amays. Some of the experimental and analytical volt-time characteristics are shown in Figs. 1 - 6. 


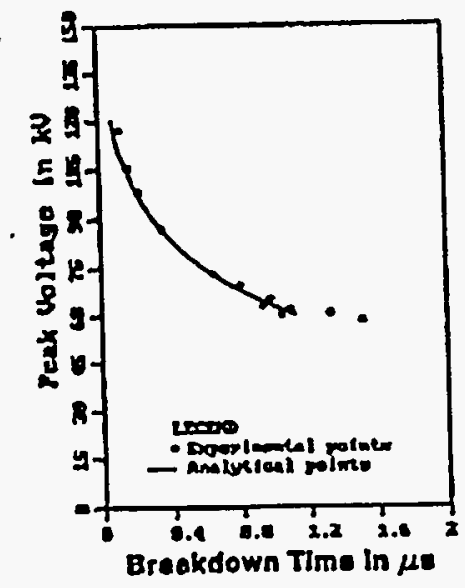

(a)

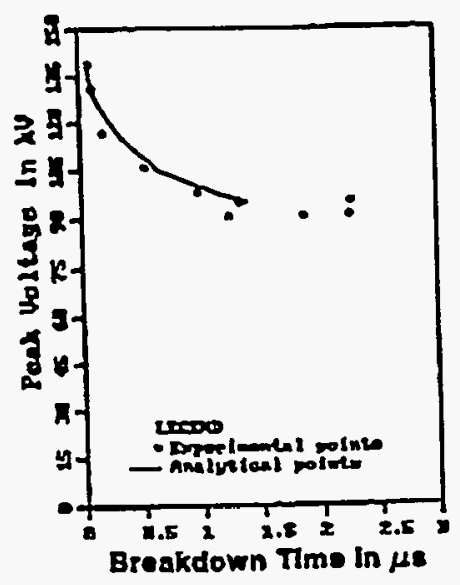

(b)

Fig. 1 Volt-tIme characteristics of 5-cm rod-plane air gap under $0.02525-\mu$ s impulse voltage.

(a) positive polarity; (b) negative polarity

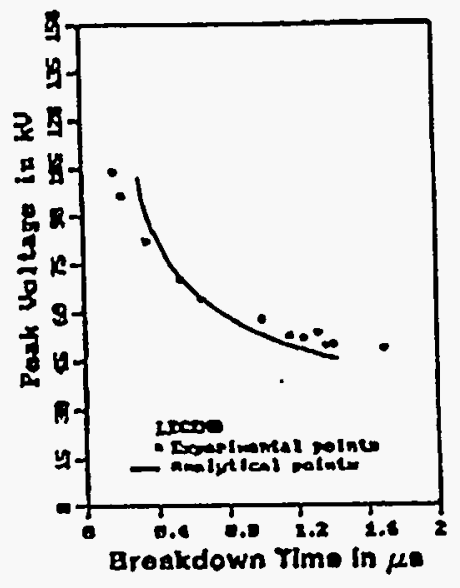

(a)

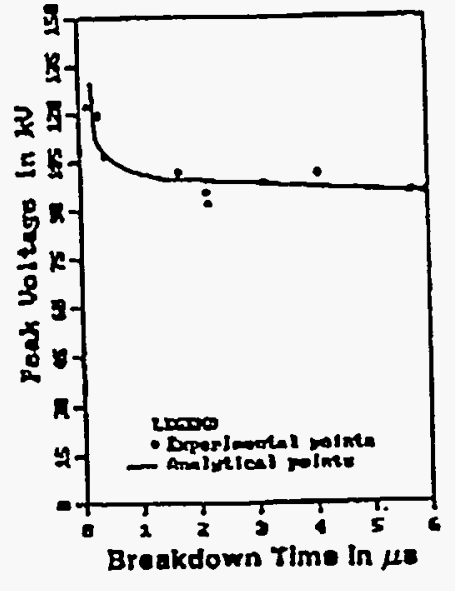

(b)

Fig. 2 Volt-time characteristles of 5 -cm rod-plane air gap under $0.12 / 25-\mu \mathrm{s}$ Impulse voltage.

(a) positive polarity; (b) negative polarity

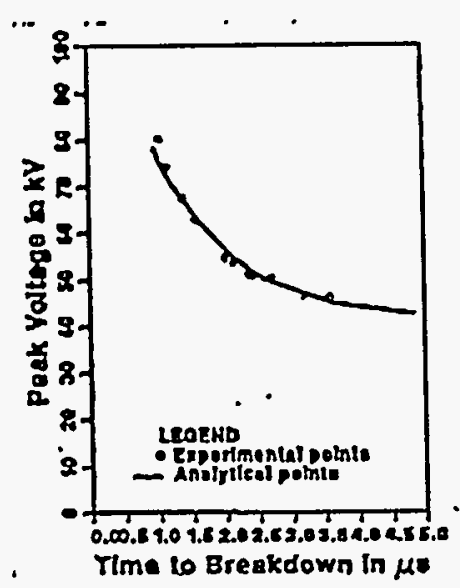

(a)

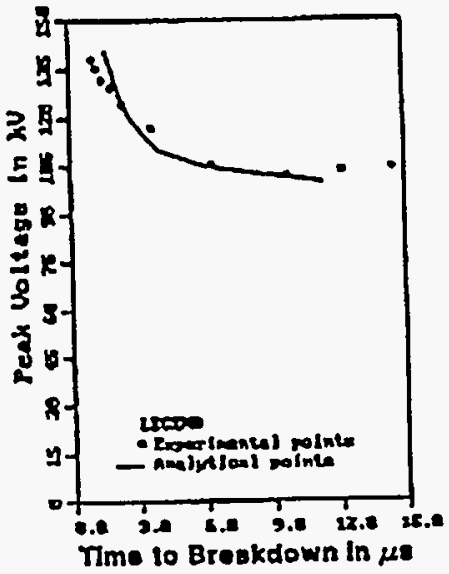

(b)

Fig. 3 Volt-time characteristics of 5-cm rod-plane alr gap under 1.2/50- $\mu$ s lmpulse voltage.

(a) positive polarity; (b) negative polarity 


\section{DISCUSSION}

According to the proposed analytical method, $D E, V_{0}$ and the exponent, $\propto V(t) / V_{\infty}$ are functions of the air gap (type and length) and the applied voltage waveshape. These differences are shown in Tables II and III. There is no similarity in $V_{0} \alpha$ and DE between the rod-plane and the rod-rod gaps when stressed by voltages of the same waveshape. For the rod-plane gap where the critical breakdown volrage levels, $V_{s 0}$, are significantly different between the two polarities [S], the three volt-time parameters are also significantly different.

TABLE II: VOLT-TUME PARAMETERS FOR 5-cm ROD.PLANE AIR GAP

\begin{tabular}{|c|c|c|c|c|c|}
\hline $\begin{array}{l}\text { Waveshapo } \\
\text { ( } \mu s)\end{array}$ & Polarity & $\begin{array}{l}v_{s_{\infty}} \\
(K V)\end{array}$ & (kv) & $\alpha$ & $D E$ \\
\hline \multirow[t]{2}{*}{$0.025 / 0.5$} & + & 88.3 & 63.30 & 0.10 & 0.97 \\
\hline & $=$ & 119.0 & 75.09 & 0.23 & $5.19^{\circ}$ \\
\hline \multirow[t]{2}{*}{$0.025 / 25$} & + & 61.3 & 27.76 & 0.11 & 9.13 \\
\hline & - & 92.0 & 70,47 & 0.35 & 82.36 \\
\hline \multirow[t]{2}{*}{0.1225} & + & 50.3 & 38.80 & 0.25 & 6.45 \\
\hline & - & 93.4 & 72.57 & 1.00 & $1.5 e 6$ \\
\hline \multirow[t]{2}{*}{$1.2 / 50$} & + & 49.2 & 40,30 & 0.24 & 21.80 \\
\hline & - & 101.9 & 83.98 & 0.50 & $2.4 \mathrm{e}$ \\
\hline
\end{tabular}

TABLE III: YOLT-TMMEE PARAMIETERS FOR 5-cm ROD-ROD AIR GAP

\begin{tabular}{|c|c|c|c|c|c|}
\hline $\begin{array}{c}\text { Waveshape } \\
\text { (us) }\end{array}$ & Polarity & $\begin{array}{l}v_{s} \\
\text { (kV }\end{array}$ & (kv) & $a$ & $D E$ \\
\hline \multirow[t]{2}{*}{0.025125} & + & 70.0 & 43.34 & 0.18 & 14.36 \\
\hline &. & 68.4 & 46.95 & 0.18 & 10.3] \\
\hline \multirow[t]{2}{*}{0.2225} & + & 54.6 & 40.33 & 0.18 & 11.45 \\
\hline & - & 56.9 & 44.23 & 0.22 & 22.95 \\
\hline \multirow[t]{2}{*}{1.2150} & + & 56.6 & 31.18 & 0.13 & 18.25 \\
\hline & - & 59.0 & 30.62 & 0.16 & 52.50 \\
\hline
\end{tabular}

The volt-time characteristics of the rod-rod gap with the $0.025 / 0.5-\mu$ s wave could not be analytically drawn because of the large scatter in the breakdown times. Similarly, the analytical volt-time curves for the rod-plane gap (under positive-polarity voltage) and the rod-rod gap (under voltages of both polarities) with the 10/100- $\mu$ s wave could not be drawn because of the breakdown on the wavefront at low amplindes. The relatively long breakdown time lag under the $0.025 / 0.5-\mu$ s wave and the breakdown on the wavefront at low amplinude of the applied voliage under the 10/100- $\mu$ s wave were discussed in [S].

Three shots of the 10/100- $\mu$ s applied voltage across the rodplane gap for the same charging voltage of the impulse generator are shown in Fig.7. The gap broke down during the first shot (bottom) after a long time delay, withstood the second shot (middle), but broke down at a low amplitude on the front (upper) during the third shot. Figure 8 shows the experimental and the analytical volt-time characteristics of the rod-plane gap under the negative-polarity $10 / 100$ - $\mu$ s wave, where low voltage level for front-of-wave breakdown was not observed. The anomalous breakdown phenomenon of the rod-rod gap under the $10 / 100$ - $\mu \mathrm{s}$ wave for both polarities is shown in Fig.9.

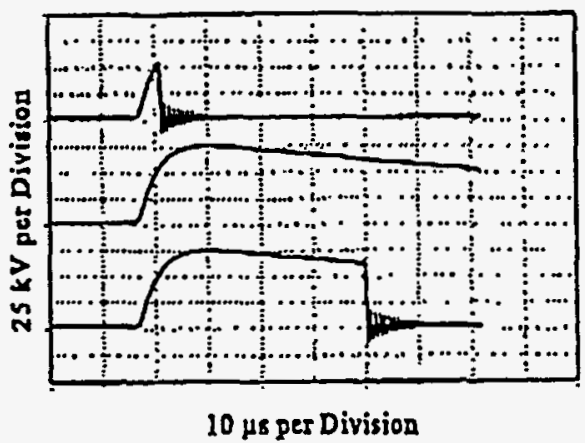

Fig.7 Three shots of applied voltage across $5-\mathrm{cm}$ rod-plane gap with positive-polarity $10 / 100-\mu s$ wave at the same charging voltage level of impulse generator.

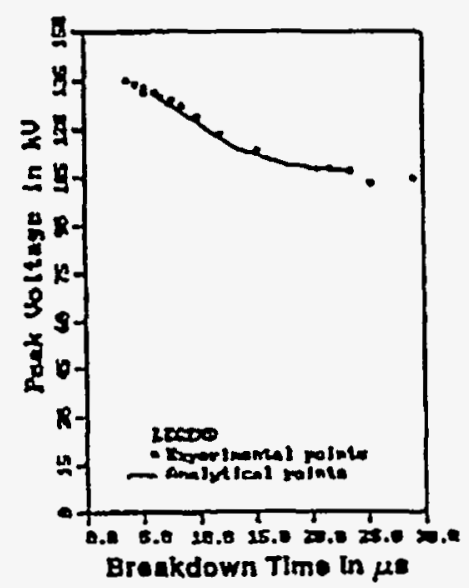

Fig.8 Volt-time characeteristle of $5-\mathrm{cm}$ rod-plane sir gap under negative-polarity $10 / 100$-ps wave. 


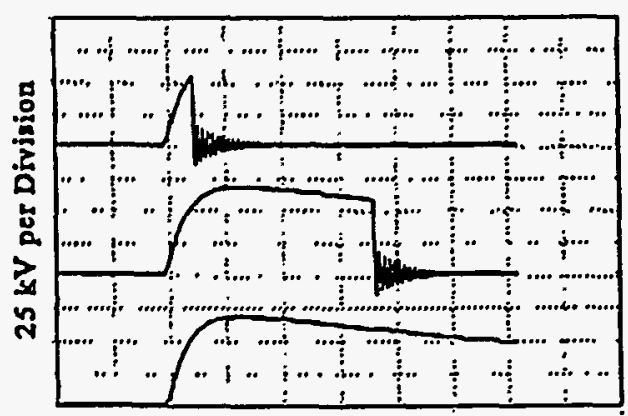

$10 \mu s$ per Division

(a)

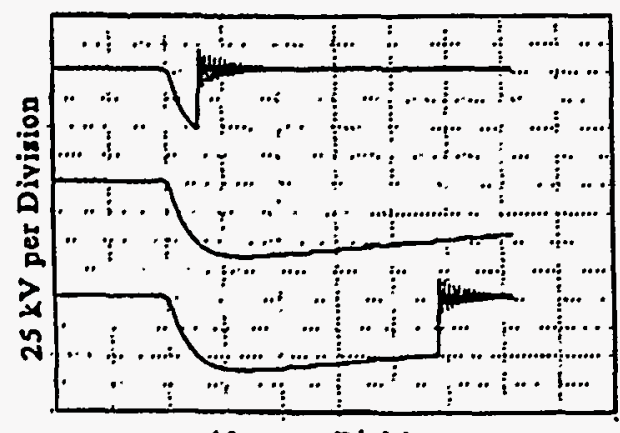

10 ps per Division

(b)

Fig.9 Three shots of applied voltage across 5-cm rod-rod air gap with 10/100- $\mu$ soltage wave at the same charging voltage level of impulse generator.

(a) positive polarity; (b) negative polarity

\section{CONCLUSIONS}

The concept of the disruprive effect (DE), as originally proposed by Witzke and Bliss, is very effective in the determination of the time lag characteristics of an air gap. However, $\mathrm{DE}$, the withstand voltage $\left(\mathrm{K}_{1}\right)$ and the exponent of the voltago $\left(\mathrm{K}_{2}\right)$ are not constants for a particular gap, as generally assumed. These parameters are functions of the applied volcage waveshape. $\mathrm{K}_{2}$ in addition, is a function of time; it varies with time during the application of the voltage. These parameters can be experimentally determined.

To be of practical value to the design engineer, the parameters for the disnuptive effect must be determined analytically. Quantitative knowledge of the physics of progression of ionization across the gap will be needed to accomplish that.
Tho breakdown on the front of the applied $10 / 100-\mu$ s voltage at relativeiy low amplitude will make insulation coordination difficult. This observation, made here and in [S], should be independently verified by other researchers.

\section{ACKNOWLEDGMENT}

This project was sponsored by the Office of Energy Management of the U.S. Deparment of Energy (DOE) under contract DE-AC05-840R21400 with Lockheed-Martin Energy Systems, Inc. through the Power Systems Technology Program of the Oak Ridge National Laboratory. It was also co-sponsored by the Center for Electric Power at the Tennessee Technological University. We acknowledge the assistance of P.M. Martin in the performance of this project.

\section{REFERENCES}

1. R.L. Wizke and T.J. Bliss, "Surge Protectlon of Cable-Connected Equipment", AIEE Trans, Vol. 69, R. I, pp. 527-542, 1950.

2. R.L. Wizke and T.J. Bliss, "Co-ordinetion of Lightning Arrester Location with Transfomer Insulation Level". Ibld, Vol. 69, P. I. Pp. 964-975, 1950.

3. IEEE/PES Task Forec Report "Review of Research on Nonstandard Lightring Vollage Weves", IEEE Trans on Power Dellvery, Vol. 9, No. 4. pp.1972-1981, 1994 .

4. IEEERES Task Foree Reporh "Bibliography of research on Nonstandard Lightning Voltage Waves", 18ld., Vol. 9, No. 4. pp.1982-1990, 1994.

5. P. Chowdhurd, A.K. Mishra, P.M. Martin and B.W. McConnelt. "The Effects of Nonstandard Lighming Voliage Waveshapes on the Impulse Strength of Shor Air Gaps", ibid, Vol. 9, No. 4, pp. 1991-1999, 1994.

6. D.B. Owen, Handbook of Sratistical Tobles. Reading, MA: Addison-Wesly Publishing Co., Inc, P.126, 1962.

Pritindra Chowdhud (M'52.SM'60) recelved B.Sc. in Physics and M.Sa in Applied Physics from Caleuma University. M.S. in Electrical Engincering from IIlinois Insitute of Technology and D.Eng. from Rensselaer Polytechnic Instarte. After worling for the industry for over 30 years, he joined the Center for Electric Power, Tennessec Teehnological University es professor of ciectrical enginearing in 1986.. He is a member of the Power Engineering Society, Industry Applications Soctery, Electromagnetic Compatibility Socicty, Dielectries and Ejectrical Insulation Society, and or CIORE.

Ashok K. Mlshra (Student Member, IEEE) received B.S. from the Regional Engineering College. Rourkele indie, and M.S. from the Tennessee Technonogled University. He is now a Ph.D. candidate ar Tennessec Tech. His primary areas of interest are high volusge, power systems and power electronics.

Benlamin W. MeConnell (M'82-SM'87) received B.S. in Physics and Mathematics from East Tennessee State University, M.S. in Physles and Ph.D. in Pbyslcs-Nuclear Science from Virglnia Polytechnic Institutc. Prior to joining ORNL, Ben was with Carolina Power and Light Company where he was the Principal Engineer for Energy research. His work at Curolina Power included a variety of research activiries ranging from nuclear safety to lond management. He has also worked af the Savannah River Laboratory in nuelear safety, reactor physics and neutuon transporm methods. 


\section{DISCLAIMER}

This report was prepared as an account of work sponsored by an agency of the United States Government. Neither the United States Government nor any agency thereof, nor any of their employees, makes any warranty, express or implied, or assumes any legal liability or responsibility for the accuracy, completeness, or usefulness of any information, apparatus, product, or process disclosed, or represents that its use would not infringe privately owned rights. Reference herein to any specific commercial product, process, or service by trade name, trademark, manufacturer, or otherwise does not necessarily constitute or imply its endorsement, recommendation, or favoring by the United States Government or any agency thereof. The views and opinions of authors expressed herein do not necessarily state or reflect those of the United States Government or any agency thereof. 


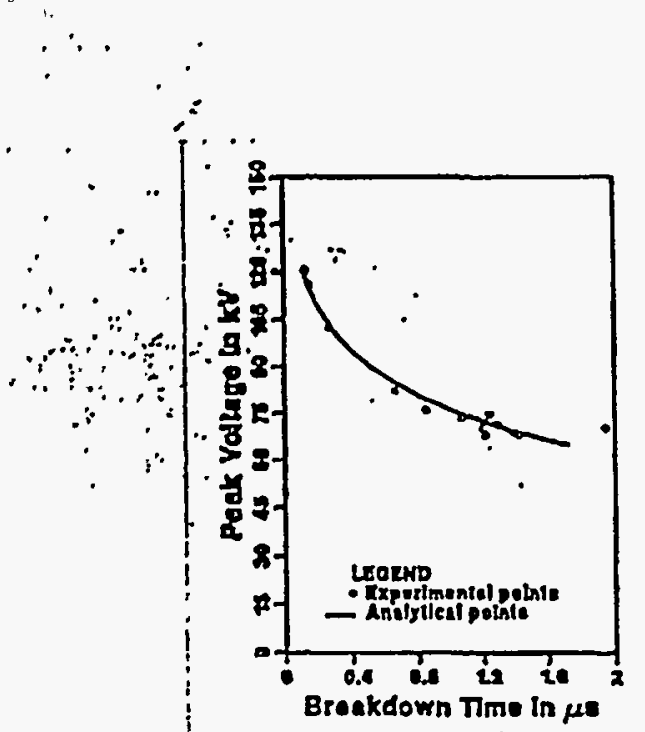

(a)

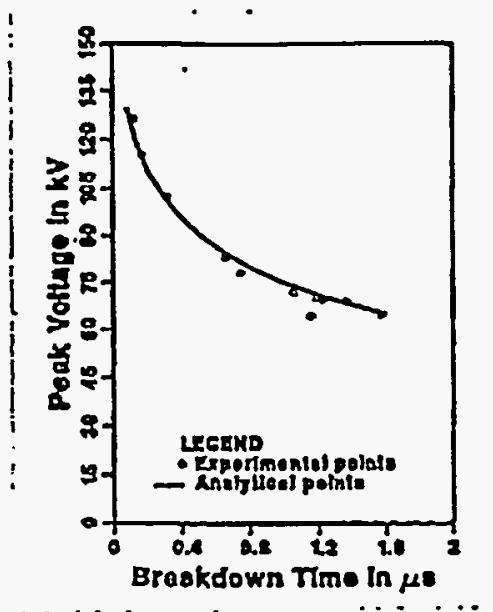

(b)

Fig. 4 Volt-time characteristics of 5-cm rod-rod air gap under $0.025 / 25$ - $\mu$ s impulse voltage.

(a) positive polarity; (b) negative polarity

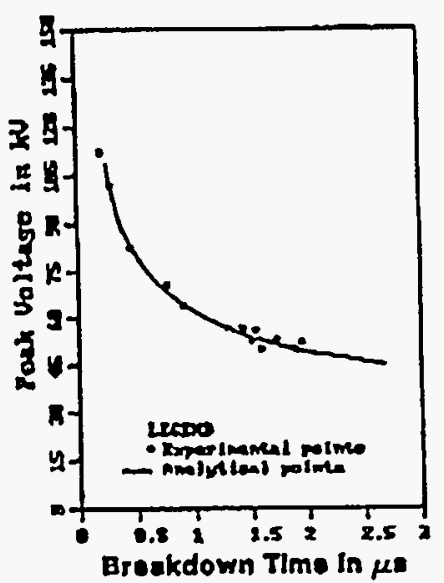

(a)

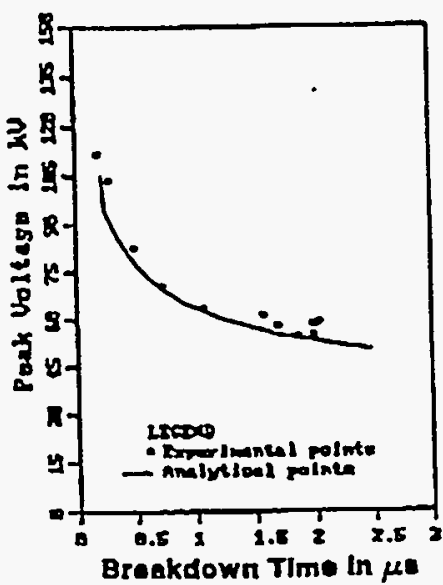

(b)

Fig. 5 Volt-time characteristics of 5-cm rod-rod air gap under $0.12 / 25$ - $\mu$ s impulse voltage.

(a) positive polarity; (b) negative polarity

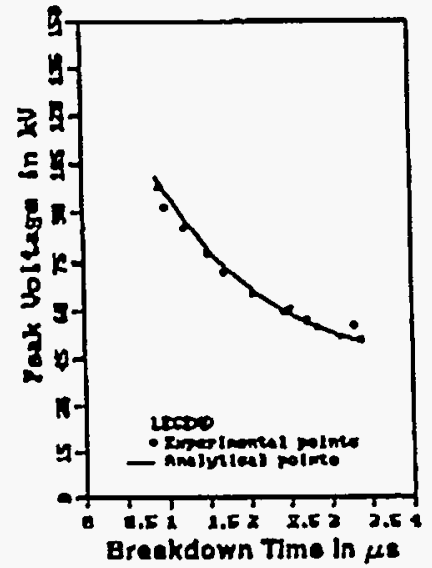

(a)

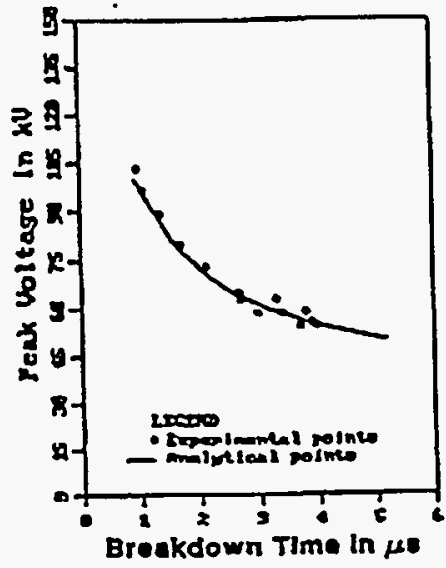

(b)

Fig. 6 Volt-time characteristics of 5-cm rod-rod air gap under 1.2/50- $\mu$ s impulse voltage. (a) positive polarity; (b) negative polarity 